\title{
Erratum: "Transmission spectra changes produced by decreasing compactness of opal like structures" [J. Appl. Phys. 105, 024910 (2009)]
}

A. Andueza, R. Echeverría, P. Morales, and J. Sevilla

Citation: Journal of Applied Physics 109, 019902 (2011); doi: 10.1063/1.3524566

View online: https://doi.org/10.1063/1.3524566

View Table of Contents: http://aip.scitation.org/toc/jap/109/1

Published by the American Institute of Physics

\section{Articles you may be interested in}

Geometry influence on the transmission spectra of dielectric single layers of spheres with different compactness Journal of Applied Physics 107, 124902 (2010); 10.1063/1.3434529

Transmission spectra changes produced by decreasing compactness of opal-like structures Journal of Applied Physics 105, 024910 (2009); 10.1063/1.3068475

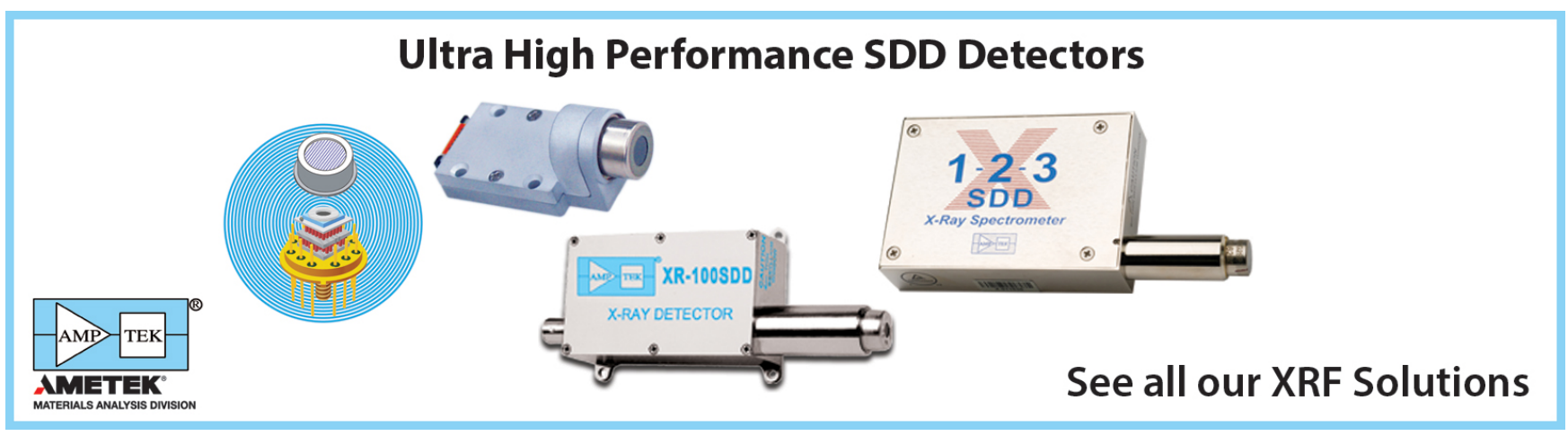




\title{
Erratum: "Transmission spectra changes produced by decreasing compactness of opal like structures" [J. Appl. Phys. 105, 024910 (2009)]
}

\author{
A. Andueza, ${ }^{\text {a) }}$ R. Echeverría, P. Morales, and J. Sevilla ${ }^{\text {a) }}$ \\ Departamento Ingeniería Eléctrica y Electrónica, Universidad Pública de Navarra, Campus de Arrosadia, \\ 31006 Pamplona, Spain
}

(Received 4 November 2010; accepted 8 November 2010; published online 5 January 2011)

[doi:10.1063/1.3524566]

Performing a systematic review of our experimental data, we have realized that we introduced a significant mistake in our abovementioned publication. Figure 3 did not correspond to the situation described, and should be changed by one here included. The corrected data do not invalidate the conclusions presented in the original publication, even more they are reinforced.

In the figure we can see a relatively small peak, around $\Lambda / \lambda=0,28$ in the compact case and 0,38 in the non compact one and a sharper and deeper peak can be seen (placed at $\Lambda / \lambda=0,50$ and 0,51 in each spectra in Fig. 3) in both lattices. Except for the frequency shift in the first peak, the spectrum does not change significantly: in the higher order rejected band transmittance values for both lattices present the same drop around $\Lambda / \lambda=0,50$ although the structure of the band (below 20 $\mathrm{dB})$ is different.

The frequency shift with compactness of the low frequency peak is well explained considering the Bragg reflection of the sphere planes. While the lack of frequency change in the higher order rejected band is caused by the physical origin of this band, strongly based in the resonant properties of the spheres. ${ }^{27}$ Therefore, the position of this band in the spectrum is determined by the Mie modes of the isolated sphere, with a significantly lower effect of their geometrical disposition. This influence of the geometrical disposition of the spheres on the higher order rejected band, presented as "low" in the original, is shown to be almost negligible by the corrected data here presented.

${ }^{27}$ L. A. Dorado, R. A. Depine, G. Lozano, and H. Miguez, Opt. Express 15, 17754 (2007).

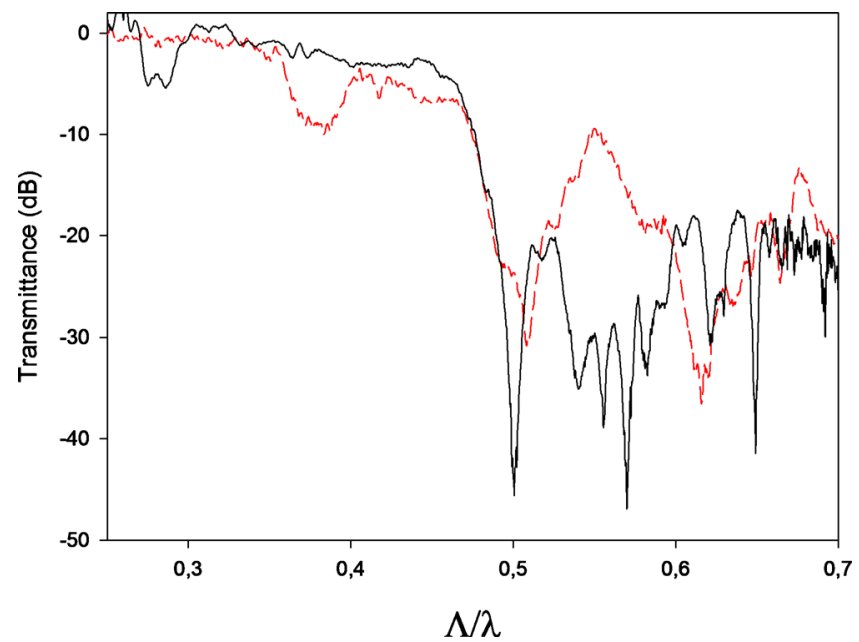

FIG. 3. (Color online) Transmission spectra of close packed (solid line) and nonclosed packed (dashed line) fcc opal like structures of $8 \mathrm{~mm}$ glass spheres. The frequency is normalized by $\omega \Lambda / 2 \pi c$.

a)Electronic addresses: angel.andueza@unavarra.es and joaquin.sevilla@unavarra.es. 